Article

\title{
Development of New Algorithm for Aniline Point Estimation of Petroleum Fraction
}

\author{
Kaiyue Wang ${ }^{1}$, Xiaoyan Sun ${ }^{1}$, Shuguang Xiang ${ }^{1, *}$ and Yushi Chen ${ }^{1,2}$ \\ 1 Institute for Process System Engineering, Qingdao University of Science and Technology, Qingdao 266042, \\ China; wky18724773718@163.com (K.W.); sun_xyan@163.com (X.S.); hez@zju.edu.cn (Y.C.) \\ 2 Petro-Cyber Works Information Technology Company Limited Shanghai Branch, Shanghai 200120, China \\ * Correspondence: xsg@qust.edu.cn
}

Received: 10 October 2019; Accepted: 26 November 2019; Published: 3 December 2019

check for updates

\begin{abstract}
The aniline point (AP) is an important physical property of a petroleum fraction. The AP gives an indication of the aromatic hydrocarbon content in a hydrocarbon mixture and can also be an indicator of the ignition point of a diesel fraction. In this study, common estimation methods were introduced and evaluated, and their limitations were analyzed. Multiple linear regression was used in constructing a quantitative function to solve for the AP using the average boiling point and specific gravity. The iterative modification algorithm of the ternary interaction algorithm was used to obtain the predicted value of the petroleum fraction AP, and the proposed algorithm was tested using 127 actual petroleum fractions. The average estimation deviation of the proposed method was $3.55 \%$; hence, compared to the commonly used estimation methods, the prediction accuracy was significantly improved. This method offers important practical value in the calculation of the petroleum fraction $\mathrm{AP}$ and other petroleum fraction properties, thereby providing reference significance.
\end{abstract}

Keywords: aniline point; petroleum fraction; estimation; multiple linear regression; algorithm

\section{Introduction}

During the petroleum (such as gasoline and diesel oil) production process, the real-time monitoring of oil products is the most direct means of ensuring production safety and maintaining oil quality stability. The aniline point (AP) [1] is defined as the lowest temperature at which an equal volume of aniline $(\mathrm{C} 6 \mathrm{H} 7 \mathrm{~N})$ is completely miscible with the tested sample. The AP temperature contributes to the characterization of pure hydrocarbons and the analysis of hydrocarbon mixtures. It is commonly used to estimate the aromatic content of petroleum, and it is therefore important for determining the composition of petroleum fractions and the quality of petroleum products. Petroleum feedstocks with high APs have higher alkane contents and lower amounts of aromatics and naphthenes. APs can also be used to calculate petroleum fraction properties, such as combustion heat, the hydrogen content, the diesel index, and the smoke point $[2,3]$.

At present, experimental methods for determining the AP are usually developed according to the domestic general standard, GB/T 262-2010 [4]. Equal volumes of aniline and the solvent to be tested are mixed, the mixture is heated at a constant rate until the two phases become completely miscible, and then the mixture is cooled at a constant rate. The temperature at which the two phases separate is recorded as the AP. In general, a higher content of aromatics results in a lower AP, while a higher alkane content results in a higher AP. The AP of cycloalkane and olefin is somewhere between these values. When experimental values of APs are not available or cannot be determined, a convenient and rapid method for predicting the APs must be used [5]. Yonggang has suggested that the aniline purification level and the cooling rate have a significant influence on AP determination [2]. It is very difficult to determine the AP of the petroleum fraction experimentally. Huizhen combined an 
artificial neural network (ANN) and the group contribution method to predict petroleum fraction physical properties and substituted the predicted value of the group into the AP ANN model to improve the estimation accuracy [3]. Farhad used a genetic algorithm and multiple linear regression to statistically validate molecular descriptors in pure hydrocarbons and returned multilinear models to generate neural networks to effectively predict pure hydrocarbon APs [1,5], which were pure components. some new methods have also been provided to estimate APs, e.g., Yinyan conducted a quantitative structure-property relationship (QSPR) study on the APs of 126 hydrocarbons from a molecular structure perspective and realized a function predicting the APs of hydrocarbons based on their molecular structure [6]. Although the above methods are advanced, they are not suitable for engineering computing applications, and their accuracy has not been systematically verified. On the basis of the difference in the properties of the estimated materials, the aniline point estimation method can be divided into a pure component aniline point estimation method and a petroleum fraction aniline point estimation method. At present, methods for estimating models, such as the genetic algorithm-multiple linear regression (GA-MLR), have been established, and structural parameters reflecting molecular structure information are calculated based on molecular structure. This method uses a genetic function algorithm to select the structural parameters that are closely related to the aniline point of hydrocarbons from many structural parameters. The algorithm then uses these parameters as a molecular description to characterize the structural characteristics of the corresponding compounds. Thereafter, multiple linear regression is used to establish predictive hydrocarbons. Using this model, the target properties can be quickly calculated and predicted, and the kinetic energy of the aniline point of hydrocarbons can be predicted according to the molecular structure. This is of great significance in the estimation of aniline points of petroleum fractions.

In the estimation process of the petroleum fraction model, there are enormous challenges to accurately estimating its characteristics [7-9] due to the diverse components in the material. Therefore, on the basis of the analysis and fitting of petroleum fraction physical properties, it is good to establish an aniline point estimation model for petroleum fractions. Actual estimation methods that are commonly used in domestic and foreign research include the American Petroleum Institute (API) method [10], Winn method [11], Linden method [12], Walsh-Mortimer method [13], and Albahari method [14]. The estimation of APs has also been researched extensively by local scholars, including Chen Xionghua [15] and Shoude Qing [16]. However, these algorithms have certain defects in terms of practical applications: the accuracy of the Winn method depends on the accuracy of the input parameters; the limitation of the Linden method is that the correlation was originally developed based on only 37 original datapoints, and hence the estimation of other petroleum fractions may induce a large deviation; the difficulty of the Walsh-Mortimer method is that it is necessary to accurately find a normal paraffin with the same normal boiling point and average boiling point; a model extrapolation of the Shoudeqing method cannot be applied to a wide range of petroleum fractions, and the verification experiment is performed afterward; and the Albahri method uses the refractive index as a basic characteristic variable (the effect is unknown, which will be further verified below). Evaluation results of the above seven commonly used model evaluations have demonstrated that the API and Chen-Xionghua methods exhibit the lowest deviation from the AP estimation, and an analysis of the correlation formula has indicated that the average boiling point and specific gravity (the API gravity is calculated by the specific gravity) have a significant effect on the AP. The AP is not just linearly associated with the average boiling point or specific gravity, but it is also related to the interaction between the two parameters [17]. The aniline point estimation methods that have been established by the group contribution method, artificial neural networks, and genetic algorithms have mostly been used for the estimation of pure hydrocarbon aniline points. Due to the special nature of the petroleum fraction, the aniline point should be estimated using an empirically relevant method.

This study introduces seven methods that are commonly used in the estimation of APs in petroleum fractions. An analysis and evaluation of these methods is presented. A new algorithm is proposed to improve the accuracy of AP estimation. 


\section{Common AP Estimation Methods and Evaluation}

\subsection{Common AP Estimation Models}

\subsubsection{API Method}

The API Technical Data Book uses the mean average boiling point, specific gravity, and Watson characteristic factor of the petroleum fraction to predict the petroleum fraction AP, according to the following model [10]:

$$
\begin{gathered}
A P=-969.65-0.139 M e A B P+59.889 K_{w}+482.611 S G, \\
K_{w}=\frac{1.8 M e A B P^{1 / 3}}{S G} .
\end{gathered}
$$

\subsubsection{Winn Method}

In the Winn method, the AP is obtained from the correlation between the mean average boiling point and the API gravity or specific gravity [11]. According to the Winn nomogram, the aniline point can also be obtained from the correlation between the mean average boiling point and the API gravity or specific gravity as follows: take the point mapping, use the quasi-Newton method (BFGS) and the general global optimization method for fitting, and get the correlation of $R=1$, as shown in Figure 1

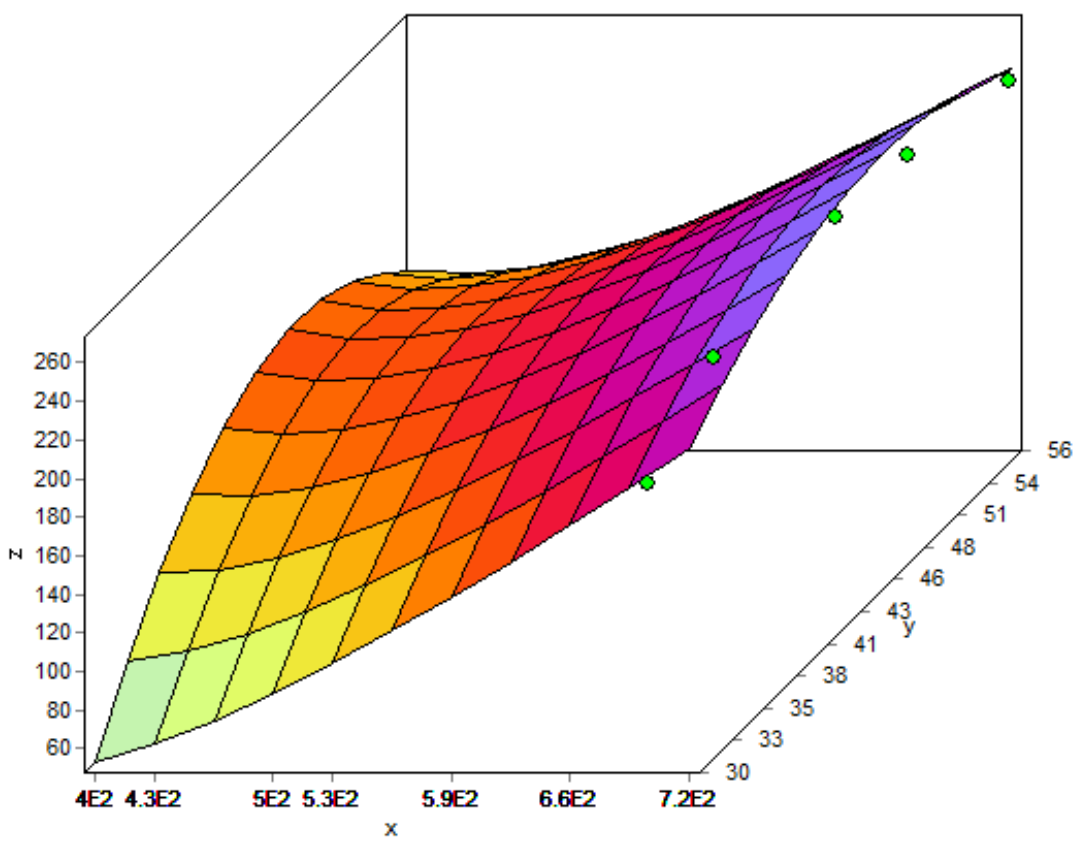

Figure 1. Molecular weight and characteristic factors of the petroleum fractions proposed by Winn.

Equation (3) is

$$
\begin{aligned}
& A P=316.66-\frac{1223.20}{1+((M e A B P-28.62) / 175.55)^{2}}-\frac{2.59}{1+\left(1+((31.40-A P I) / 3.20)^{2}\right)} \\
& -\frac{32.65}{\left(1+((M e A B P-28.62) / 175.55)^{2}\right)\left(1+((31.40-A P I) / 3.20)^{2}\right)}
\end{aligned}
$$




\subsubsection{Linden Method}

According to the characterization methods of Watson and Nelson, the approach proposed by Linden uses the API gravity and mean average boiling point to predict the AP of the petroleum fraction [12], as follows:

$$
\begin{gathered}
A P=-183.3+0.27 A P I \cdot M e A B P^{1 / 3}+0.317 M e A B P, \\
A P I=\frac{141.5}{S G}-131.5 .
\end{gathered}
$$

\subsubsection{Walsh-Mortimer Method}

On the basis of the study of gas chromatography, Walsh and Mortimer proposed that the AP is predicted by a polynomial of the carbon content and the specific gravity of normal paraffin, with the normal boiling point equal to the mean average boiling point $[13,18]$ :

$$
\begin{gathered}
A P=-204.9-1.498 C_{50}+\frac{100.5 C_{50}^{1 / 3}}{S G}, \\
C_{50}=\frac{M_{P}-14}{2}, \\
M_{P}=\left[\frac{6.98291-\ln (1070-M e A B P)}{0.02013}\right]^{3 / 2} .
\end{gathered}
$$

\subsubsection{Albahri Method}

This method uses the refractive index as a basic characteristic parameter to predict the AP of the petroleum fraction $[14,19]$ :

$$
\begin{gathered}
A P=-9805.269 R_{i}+711.85761 S G+9778.7069, \\
R_{i}=n_{20}-\frac{d_{20}}{2}, \\
n_{20}=\left(\frac{1+2 I}{1-2 I}\right)^{\frac{1}{2}}, \\
I=0.012419 M e A B P^{0.006438} S G^{-1.6117} e^{0.0007272 M e A B P+3.3223 S G-0.0008867 M e A B P \cdot S G,} \\
d_{20}=S G-0.0045(2.34-1.9 S G) .
\end{gathered}
$$

\subsubsection{Chen-Xionghua (Chen)}

In this method, the API gravity and the mean average boiling point of 65 petroleum fractions are used as the parameters, and the measured AP value is employed as the standard to fit the correlation formula [15]:

$$
A P=-140.9942+3.6913 A P I+0.4618 M e A B P-0.0224 A P I^{2}-0.00025305 M e A B P^{2} .
$$




\subsubsection{Shoude Qing (Shou)}

By measuring 174 petroleum fractions of six representative crude oils, including Daqing, Shengli, Dagang, Renqiu, Gudao, and Yangsanmu, as well as the catalytic cracking distillates of Daqing and Shengli (reforming and extracting oil) and the winning coking fractions, the physical properties (e.g., the mean average boiling point, density, and AP) of 95 petroleum fractions of representative secondary processing oils are determined. Using the above data as parameters, the empirical correlation of the estimated AP is obtained through Equation (15) $[7,16]$ :

$$
A P=1.63677 \times 10^{-5} M e A B P^{2.29383} S G^{-4.40113} .
$$

\subsection{Data Sources}

From the actual oil products provided by the factory, 24 petroleum fractions within the applicable range were selected for testing and compared to the measured values. These 24 petroleum fractions were from the literature [3]. The average relative deviation (ARD) and average absolute deviation (AAD) of the predicted results were calculated. The oil APs used for verification ranged from 45 to $107^{\circ} \mathrm{C}$, the average boiling point ranged from 115 to $545^{\circ} \mathrm{C}$, and the API gravity ranged from 14 to 56 .

\subsection{Evaluation Results}

A comparison of the evaluation results of the seven algorithms introduced above is presented in Table 1.

Table 1. Error analysis of existing aniline point (AP) estimation methods. ARD: average relative deviation; AAD: average absolute deviation.

\begin{tabular}{ccc}
\hline Method & ARD (\%) & AAD $\left({ }^{\circ} \mathbf{C}\right)$ \\
\hline API Method & 7.31 & 5.44 \\
Winn Method & 28.32 & 10.65 \\
Walsh-Mortimer Method & 9.46 & 6.74 \\
Linden Method & 12.28 & 12.93 \\
Albahri Method & 10.66 & 15.07 \\
Chen Method & 9.83 & 6.46 \\
Shou Method & 22.54 & 19.11 \\
\hline
\end{tabular}

As can be observed from Table 1, the AADs of the seven estimation methods were $5.44{ }^{\circ} \mathrm{C}$, $10.65{ }^{\circ} \mathrm{C}, 6.74{ }^{\circ} \mathrm{C}, 12.93{ }^{\circ} \mathrm{C}, 15.07^{\circ} \mathrm{C}, 6.46^{\circ} \mathrm{C}$, and $19.11^{\circ} \mathrm{C}$. The ARDs of the seven methods were approximately $7.31 \%$ to $28.32 \%$, and the minimum ARD was above $5 \%$. The error in the method was obtained as follows: the accuracy of the Winn method depends on the accuracy of the input parameters. The limitation of the Linden method is that the correlation was originally developed based on only 37 original datapoints. Thus, the estimated ARD for other petroleum fractions was $12.28 \%$. The difficulty of the Walsh-Mortimer method is that it is necessary to accurately determine normal paraffin with the same normal boiling point and medium average boiling point. The estimated ARD and ADD of the Shou method were the biggest among the evaluated methods, which showed that the model extrapolation was not strong. The ARD of the Albahri method was $10.66 \%$. The ARDs of the API and the Chen-Xionghua methods were $7.31 \%$ and $9.83 \%$, which were both less than $10 \%$, indicating that using the refractive index as a basic characteristic variable is not as effective in the API method and that the model prediction effect of the Chen-Xionghua method is accurate. Although the API method showed a minimum deviation of $7.31 \%$ when estimating 24 kinds of real oil, this was still more than $5 \%$, which makes it difficult to meet the high accuracy of the actual estimation.

In summary, the commonly used AP estimation models had a medium average boiling point range of 115 to $545{ }^{\circ} \mathrm{C}$ and an API gravity range of 14 to 56. In actual oil products, the calculation results exhibited significant deviations, which is difficult to handle in practice. Therefore, estimation is 
necessary, and a more accurate AP estimation model is required. With reference to the variables used in the API method, it is suggested that a new average model and the actual values of real oil be used to return a new average correlation.

\section{New Algorithm for AP Estimation}

\subsection{Proposal of New Model for AP}

To avoid the singularity of the previous methods, the complex interactions between the three should be considered. Thus, the formula for estimating the petroleum fraction AP is as follows:

$$
A P=f(M e A B P)+g(S G)+h(M e A B P, S G) .
$$

As is indicated in Equation (16), the model consists of three parts: $f(M e A B P)$, which is affected by the mean average boiling point; $g(S G)$, which is affected by the specific gravity; and $h(M e A B P, S G)$, which is affected by the interaction between the mean average boiling point and specific gravity.

For the univariate regression terms $f(M e A B P)$ and $g(S G)$, a total of 142 actual oil data points were used, which were derived from the existing literature and measured values $[8,9,20]$. These 142 data points can be recorded in detail in Appendix A, Table A1. By employing the quasi-Newton method and using the average boiling point and specific gravity of the petroleum fraction, the objective functions of $f(M e A B P)$ and $g(S G)$ were regressed $[21,22]$ to obtain the parameters, and the correlations are presented in Equations (18) and (19), respectively.

In this case, the unit of the average boiling point is converted into ${ }^{\circ} \mathrm{F}$ :

$$
M e A B P_{R}=1.8 M e A B P-459.67,
$$

$$
\begin{gathered}
f(\mathrm{MeABP})=-19.15+0.3145 \mathrm{MeABP} P_{R}-0.0002289 \mathrm{MeABP} P_{R}{ }^{2}+7.861 \times 10^{-8} \mathrm{MeABP}_{R}{ }^{3} \\
+5.390 \times 10^{-11} \mathrm{MeABP} P_{R}{ }^{4}-4.165 \times 10^{-14} \mathrm{MeABP} P_{R}{ }^{5}
\end{gathered}
$$

According to the original model mentioned in previous articles $[3,7,8,10,11,15,16]$, it can be concluded that the AP is usually related to the mean average boiling point and specific gravity. Therefore, when the initial AP value is used, the parameters of the mean average boiling point and specific gravity (following a fitting correction) are employed. This is conducted in a proportional manner, as indicated in Equation (20), where $a$ and $b$ are weighting factors, representing the determined proportions of Equations (18) and (19) in the initial AP value:

$$
A P_{0}=a \cdot f(M e A B P)+b \cdot g(S G) .
$$

An iterative correction algorithm with a new correlation is applied for the $h(M e A B P, S G)$ component, combined with the concept of multiple linear regression of the QSPR model in the pure component [6] and using the interaction relationship between the AP, mean average boiling point, and specific gravity. Using the above 142 actual oil data types, the regression is performed according to the model-free method [22], and the iterative relationship is obtained as follows:

$$
h(\mathrm{MeABP}, S G)=\triangle A P=\frac{k_{1}-k_{2} A P_{0}-k_{3} A P_{0}^{2}-A P_{0}^{3} k_{4} / 3}{-k_{2}-k_{2} k_{3} A P_{0}-A P_{0}^{2} k_{4}}<0.0001 .
$$

The parameters are as follows:

$$
k_{1}=0.9181463 S G_{A P}+M e A B P_{A P}-133.5112,
$$




$$
\begin{gathered}
k_{2}=-0.00001261948 S G_{A P}+0.0004269, \\
k_{3}=1.367184 \times 10^{-7} S G_{A P}+4.00032 \times 10^{-6}, \\
k_{4}=0.001170141 S G_{A P}+0.17084 .
\end{gathered}
$$

When the iteration criterion indicates that the estimated AP has converged, the iteration is stopped. According to the concept of the limit, we let Equation (21) be 0 and arrange the above calculation process to obtain a one-dimensional multiple equation, which is simplified to obtain the following:

$$
\begin{aligned}
& -\left(0.0012 S G_{A P}+0.17\right) A P+\left(0.000013 S G_{A P}-0.0004\right) A P^{2}-\left(4.56 \times 10^{-8} S G_{A P}\right. \\
& \left.+1.33 \times 10^{-6}\right) A P^{3}+0.92 S G_{A P}+M e A B P_{A P}-133.51=0
\end{aligned} .
$$

At this time, the AP is determined to be the estimated AP value, and the unit is $\mathrm{K}$.

\subsection{Application of New Algorithm}

A calculation flow chart for the new AP estimation algorithm is presented in Figure 2. The estimation steps are as follows: First, according to the values of the average boiling point and specific gravity, Equations (18), (19), and (21) are applied to calculate $f(M e A B P), g(S G)$, and $h(M e A B P$, $S G)$, respectively. Thereafter, the calculated value of the previous step is incorporated into Equation (20) to obtain the initial value required for the iteration, and the iterative calculation is started. Finally, when the iterative condition is judged to converge, the calculation ends, and the estimation result is the output.

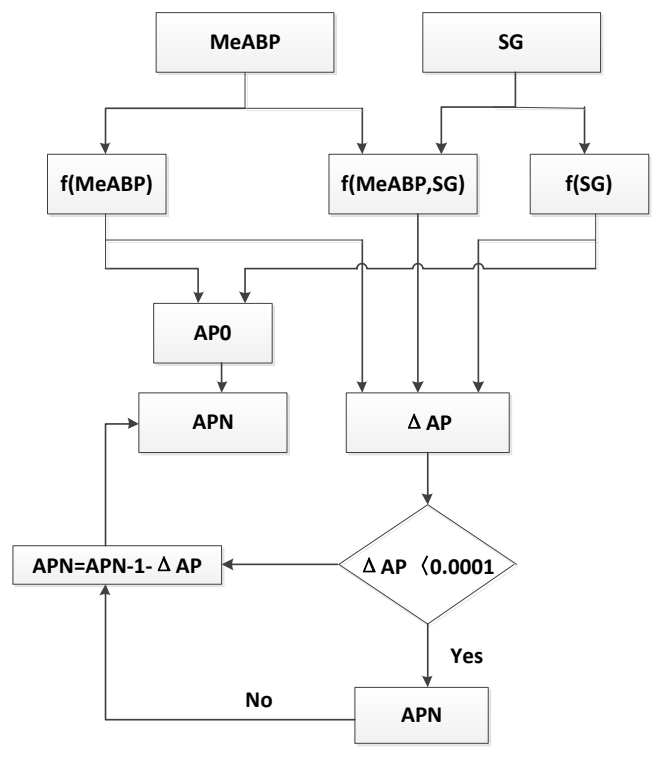

Figure 2. Proposed new model calculation flow chart.

The method has a medium average boiling point of approximately $63.33^{\circ} \mathrm{C}$ to $593.33^{\circ} \mathrm{C}$ and a specific gravity of approximately 0.65 to 1.08 . The measurement results are more accurate, and the requirements of most real oil measurements can be met.

\subsection{Cross-Validation}

As is shown in Equations (18), (19), and (22)-(25), the models presented in this paper involve 21 parameters. To facilitate differentiation, these parameters are named by different variables. The names of the parameters, source formula, and standard values in the equations are shown in Table 2. 
Table 2. Names of model parameters, source formulas, and standard values.

\begin{tabular}{ccc}
\hline Parameter Name & Source Formula & Standard Value \\
\hline$M 0$ & Equation (18) & -19.15 \\
$M 1$ & Equation (18) & 0.3145 \\
M2 & Equation (18) & $-2.289 \times 10^{-4}$ \\
$M 3$ & Equation (18) & $7.861 \times 10^{-8}$ \\
M4 & Equation (18) & $5.390 \times 10^{-11}$ \\
M5 & Equation (18) & $-4.165 \times 10^{-14}$ \\
S0 & Equation (19) & 421.5 \\
S1 & Equation (19) & -908.8 \\
S2 & Equation (19) & 879.6 \\
S3 & Equation (19) & -479.8 \\
S4 & Equation (19) & 103.6 \\
S5 & Equation (19) & 1.87 \\
K1_1 & Equation (22) & 0.9181 \\
K1_2 & Equation (22) & 1 \\
K1_3 & Equation (22) & -133.5 \\
K2_1 & Equation (23) & $-1.262 \times 10^{-5}$ \\
K2_2 & Equation (23) & $4.269 \times 10^{-4}$ \\
K3_1 & Equation (24) & $1.367 \times 10^{-7}$ \\
K3_2 & Equation (24) & $4.000 \times 10^{-6}$ \\
K4_1 & Equation (25) & $1.170 \times 10^{-3}$ \\
K4_2 & Equation (25) & 0.1708 \\
\hline
\end{tabular}

In order to verify the stability of the obtained model parameters, we cross-validated the parameters obtained using 142 datapoints. We randomly divided 142 datapoints into 10 groups (where 8 groups contained 14 datapoints and 2 groups contained 15 datapoints). We selected 9 groups as the training set and used the remaining group as the verification set for model validation. through this method, we could obtain 10 training/verification sets. In each experiment, the training set was used to train the parameters of the model, and the ARD of the obtained model was evaluated using the validation set. In addition, in order to prevent instability in random grouping stages, we repeated the experiment 21 times, that is, a total of $21 \times 10=210$ cross-validation experiments. We recorded the model parameters obtained in each experiment and the corresponding average error. For display convenience, we solved the average value of the parameters and the relative error in 30 cross-validation experiments. The results are shown in Table 3.

It can be seen from Table 3 that under the cross-validation test, the models obtained through training with partial datasets could also have high accuracy, and the ARD was basically less than $1 \%$. In addition, we also compared the average value of the parameters obtained with 210 crossover experiments to the standard parameters of the proposed model. The results showed that the deviation of 21 parameters was also within 1\%, which proved that the model parameters obtained by the 142 datapoints had high stability. 
Table 3. ARD table corresponding to the mean value of the model parameters obtained with the cross-validation experiment.

\begin{tabular}{|c|c|c|c|c|c|c|c|c|}
\hline $\mathbf{N}$ & 1 & 2 & 3 & 4 & 5 & 6 & 7 & Average \\
\hline MO & -19.02 & -19.23 & -19.11 & -19.15 & -19.21 & -19.26 & -19.16 & -19.163 \\
\hline M1 & 0.3181 & 0.3122 & 0.3147 & 0.3145 & 0.3156 & 0.3135 & 0.3122 & 0.31440 \\
\hline M2 & $-2.24 \times 10^{-4}$ & $-2.27 \times 10^{-4}$ & $-2.29 \times 10^{-4}$ & $-2.28 \times 10^{-4}$ & $-2.28 \times 10^{-4}$ & $-2.34 \times 10^{-4}$ & $-2.27 \times 10^{-4}$ & $-2.28 \times 10^{-4}$ \\
\hline M3 & $7.91 \times 10^{-8}$ & $7.94 \times 10^{-8}$ & $7.91 \times 10^{-8}$ & $7.87 \times 10^{-8}$ & $7.95 \times 10^{-8}$ & $7.98 \times 10^{-8}$ & $7.88 \times 10^{-8}$ & $7.920 \times 10^{-8}$ \\
\hline M4 & $5.39 \times 10^{-11}$ & $5.39 \times 10^{-11}$ & $5.49 \times 10^{-11}$ & $5.38 \times 10^{-11}$ & $5.37 \times 10^{-11}$ & $5.38 \times 10^{-11}$ & $5.42 \times 10^{-11}$ & $5.403 \times 10^{-11}$ \\
\hline M5 & $-3.96 \times 10^{-14}$ & $-4.12 \times 10^{-14}$ & $-4.17 \times 10^{-14}$ & $-4.16 \times 10^{-14}$ & $-4.16 \times 10^{-14}$ & $-4.15 \times 10^{-14}$ & $-4.17 \times 10^{-14}$ & $-4.127 \times 10^{-14}$ \\
\hline SO & 421.1 & 422.1 & 421.1 & 421.7 & 420.9 & 421.5 & 421.5 & 421.41 \\
\hline S1 & -911.2 & -908.4 & -910.2 & -909.1 & -909.2 & -908.3 & -907.1 & -909.05 \\
\hline S2 & 880.6 & 877.6 & 880.7 & 880.1 & 880.2 & 879.1 & 879.5 & 879.67 \\
\hline S3 & -479.1 & -479.7 & -479.8 & -479.8 & -479.5 & -480.1 & -479.9 & -479.70 \\
\hline S4 & 104.1 & 104.2 & 103.6 & 103.6 & 103.7 & 103.6 & 103.6 & 103.77 \\
\hline S5 & 1.855 & 1.867 & 1.861 & 1.875 & 1.866 & 1.876 & 1.856 & 1.8656 \\
\hline K1_1 & 0.9180 & 0.9121 & 0.9083 & 0.9182 & 0.9151 & 0.9204 & 0.9167 & 0.91554 \\
\hline K1_2 & 0.9802 & 0.9995 & 0.9994 & 1.000 & 1.000 & 1.014 & 0.9887 & 0.99740 \\
\hline K1_3 & -132.5 & -133.5 & -132.5 & -132.5 & -132.5 & -132.5 & -132.5 & -132.64 \\
\hline K2_1 & $-1.32 \times 10^{-5}$ & $-1.27 \times 10^{-5}$ & $-1.25 \times 10^{-5}$ & $-1.262 \times 10^{-5}$ & $-1.264 \times 10^{-5}$ & $-1.283 \times 10^{-5}$ & $-1.241 \times 10^{-5}$ & $-1.270 \times 10^{-5}$ \\
\hline$K 2 \_2$ & $4.289 \times 10^{-4}$ & $4.267 \times 10^{-4}$ & $4.269 \times 10^{-4}$ & $4.272 \times 10^{-4}$ & $4.271 \times 10^{-4}$ & $4.312 \times 10^{-4}$ & $4.288 \times 10^{-4}$ & $4.2811 \times 10^{-4}$ \\
\hline K3_1 & $1.357 \times 10^{-7}$ & $1.352 \times 10^{-7}$ & $1.377 \times 10^{-7}$ & $1.370 \times 10^{-7}$ & $1.367 \times 10^{-7}$ & $1.351 \times 10^{-7}$ & $1.347 \times 10^{-7}$ & $1.3601 \times 10^{-7}$ \\
\hline K3_2 & $3.979 \times 10^{-6}$ & $4.002 \times 10^{-6}$ & $3.979 \times 10^{-6}$ & $4.009 \times 10^{-6}$ & $4.009 \times 10^{-6}$ & $4.001 \times 10^{-6}$ & $4.101 \times 10^{-6}$ & $4.0114 \times 10^{-6}$ \\
\hline K4_1 & $1.163 \times 10^{-3}$ & $1.165 \times 10^{-3}$ & $1.177 \times 10^{-3}$ & $1.172 \times 10^{-3}$ & $1.210 \times 10^{-3}$ & $1.162 \times 10^{-3}$ & $1.165 \times 10^{-3}$ & $1.1734 \times 10^{-3}$ \\
\hline K4_2 & 0.1709 & 0.1801 & 0.1652 & 0.1633 & 0.1723 & 0.1710 & 0.1722 & 0.17071 \\
\hline ARD & 0.01012 & 0.00618 & 0.00749 & 0.00881 & 0.00545 & 0.00449 & 0.00960 & 0.00274 \\
\hline
\end{tabular}




\subsection{Parameter Sensitivity Analysis}

Parameter sensitivity is a good measure of the stability of an algorithm. In this section, we performed a sensitivity analysis of the 21 parameters in the proposed model. The sensitive parameters in the model could be obtained by evaluating the decline in the accuracy of the model with changing parameters. To further understand the sensitivity of the parameters, the sensitivity range of the sensitive parameters was determined.

\subsubsection{Sensitivity Analysis of Individual Parameters}

We analyzed 21 parameters in the proposed model one by one. On the basis of the standard values of the model parameters, the tested parameter was changed in each experiment, and the other 20 parameters were fixed. We used a normal distribution to sample new values of the tested parameter. The mean of the normal distribution was the standard value of the parameter, and the standard deviation was 0.2 times the parameter. For example, for a parameter with a standard value of $X$, the normal distribution was $\sim N(X, 0.2 X)$. Random sampling was performed within this normal distribution to obtain new model parameters. We used a normal distribution to sample new values of the tested parameter, and the relative errors were counted. In order to prevent large deviations in the random sampling process, we performed 20 experiments on each parameter, sampling 20 new parameters within the normal distribution of the tested parameters. The relative error of the 20 models with the new parameters was estimated, and the ARD was calculated, which was a good index of the sensitivity of the parameter. The results are shown in Table 4 .

Table 4. Sensitivity analysis of 21 parameters in the model.

\begin{tabular}{cccccccc}
\hline Parameters & M0 & M1 & M2 & M3 & M4 & M5 & S0 \\
\hline ARD & 0.012718 & 0.11784 & 0.045702 & 0.008102 & 0.003569 & 0.003712 & 1.707076 \\
Parameters & S1 & S2 & S3 & S4 & S5 & K1_1 & K1_2 \\
ARD & 0.018394 & 2.110738 & 1.558631 & 3.229368 & 0.002512 & 0.056777 & 0.059139 \\
Parameters & K1_3 & K2_1 & K2_2 & K3_1 & K3_2 & K4_1 & K4_2 \\
ARD & 0.122109 & 0.010831 & 0.004586 & 0.003963 & 0.001617 & 0.00787 & 0.016993 \\
\hline
\end{tabular}

It can be seen from Table 4 that the ARD of the parameters M1 and K1_3 reached more than 10\% under this test condition, which indicates that a little variation in the parameter involved a certain impact on the accuracy of the model; therefore, the parameter sensitivity of M1 and K1_3 was high. For the parameters S0, S2, S3, and S4, the ARD even reached more than $150 \%$, which indicates that these four parameters were extremely sensitive, and slight changes could cause large errors. The ARDs of the other 15 parameters were less than $6 \%$. The changes in the parameters had little effect on the accuracy of the model, and the sensitivity of the parameters was low. The experimental results showed that among the 21 parameters of the proposed model, six parameters (M1, K1_3, S0, S2, S3, and S4) were sensitive, and the sensitivity of S0, S2, S3, and S4 was extremely high for the aniline point prediction performed by this model. An adjustment of these parameters should be carefully considered.

\subsubsection{Estimation of the Sensitive Range of Sensitive Parameters}

In order to have a deep recognition of the sensitivity of the model parameters, we analyzed the sensitivity range of the sensitive parameters obtained in Section 3.4.1. In this experiment, the tested parameter variation range was set at $\pm 50 \%$ of the standard value ( $50 \%-150 \%$ of the standard value). The changing step was set at $2 \%$, that is, 51 experiments were performed for each sensitive parameter. As with the experiments in Section 3.4.1, we estimated 142 datapoints using the model (with the changed parameters) and counted the ARDs of each experiment. The ARDs of each sensitive parameter at different variation ratios are shown in Figure 3. 


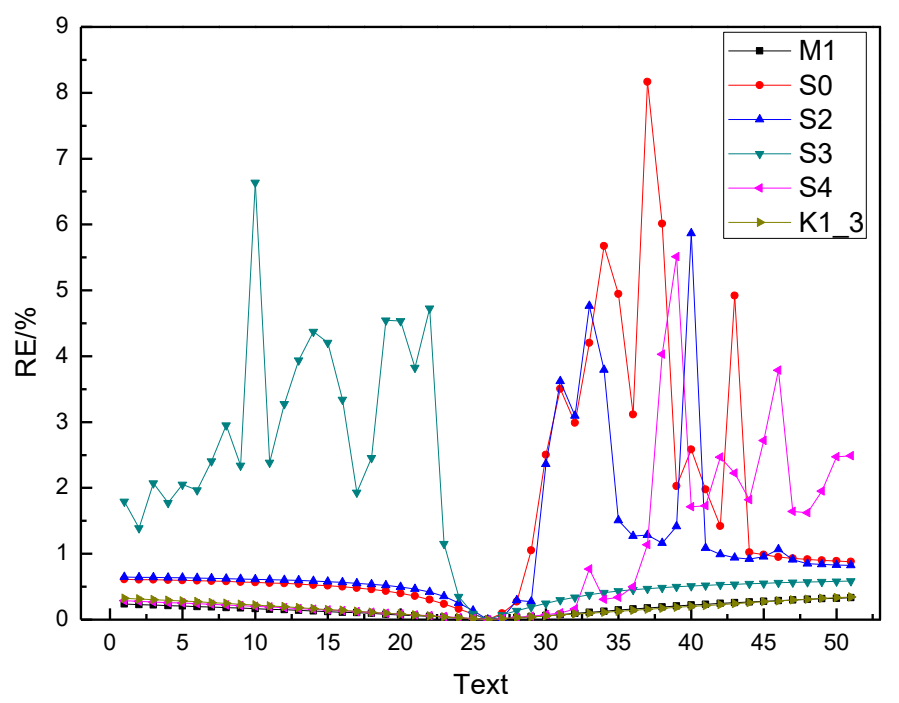

Figure 3. ARDs of the six sensitive parameters (M1, S0, S2, S3, S4, and K1_3) at varying ratios.

It can be seen from Figure 3 that for M1 and K1_3, as the parameters gradually moved away from the true value, the ARD also gradually increased. When the parameter change rate was within $\pm 15 \%$, the ARD was less than $10 \%$. Outside this range, the error was greater than $10 \%$. When the rate of change reached $40 \%$ or more, the ARD reached $20 \%$. Although these two parameters were more sensitive, as the proportion of parameter changes gradually increased, the ARD growth was also relatively stable. For parameter $\mathrm{S} 3$, when the parameter variation range was in the range of $-2 \%$ to $6 \%$, the ARD was less than $10 \%$, and when the variation was above $6 \%$, the ARD gradually increased, and the change speed was significantly higher than in M1 and K1_3. When the change was less than $-2 \%$, the ARD increased rapidly and reached more than $100 \%$ at $-6 \%$. For parameter S4, when the variation range was in the range of $-16 \%$ to $10 \%$, the ARD was less than $10 \%$. When the variation was less than $-16 \%$, the ARD gradually increased, and the rate of change was similar to that of M1 and K1_3. When the change was greater than $10 \%$, the ARD increased rapidly, and when the rate of change reached $24 \%$ or more, the ARD exceeded $100 \%$. For the parameter S0, when the variation range was within $\pm 2 \%$, the ARD was less than $10 \%$. When the variation was less than $-2 \%$, the ARD gradually increased, and the change speed was significantly higher than that of the two parameters M1 and K1_3. When the change was greater than $2 \%$, the ARD increased rapidly, and above $6 \%$, the error reached $100 \%$ or more. The condition of parameter S2 was close to S0. When the variation range was within $\pm 2 \%$, the ARD was less than $10 \%$. When the variation was less than $-2 \%$, the ARD gradually increased, and the variation was similar to S0. When it was greater than $2 \%$, the ARD increased rapidly, and at $8 \%$, the error reached $100 \%$ or more. The above results show that the four parameters S0, S2, S3, and S4 were very sensitive and had different sensitivity ranges. When M1 and K1_3 increased and decreased, the relative error changed slowly. The parameter S3 was more sensitive when it was small, and the parameters S0, S2, and S4 were more sensitive when they became larger. Therefore, when using this formula for aniline point estimation, negative adjustments should be avoided for S3, and positive adjustments should be avoided for S0, S2, and S4.

\subsection{Data Source Evaluation}

The data used for the evaluation in this study consisted of two parts, some of which were from an oil- and gas-related manual [7,23-25] that collects a dataset on crude oil analysis and specifications of petroleum products globally to provide an assessment of algorithm accuracy (and therefore serves as an important reference). The other part was composed of actual measured oil data, including Tarim oil (from the literature [3]), Dagang oil, Shengli oil, Renqiu oil, Yangsanmu oil, Daqing oil, and Gudao oil $[7,15,16]$, as well as data on 44 oils collected through actual processes. The data on the oil products 
of the AP were as follows: aviation coal, catalytic hydrogenation, diesel hydrogenation, catalytic cracking, and atmospheric and vacuum reduction.

The specific gravity and medium average boiling point data of 127 petroleum fractions were selected for this study. The 127 data points used for verification can be recorded in detail in Appendix A, Table A2. The petroleum fraction was obtained through the distillation of crude oil through a real boiling point curve, covering various types of crude oil and its fractions both locally and globally. The AP of each oil was predicted by the new algorithm, and the results and relative deviations were analyzed.

\section{Evaluation Results of New AP Algorithm}

\subsection{Evaluation Results of New Algorithm}

The petroleum fraction used in the model verification had a specific gravity ranging from 0.65 to 1.10 , and the average boiling point range was $300.48-866.48 \mathrm{~K}$. A scatterplot of the predicted values using the new algorithm and the actual values of the AP is presented in Figure 4.

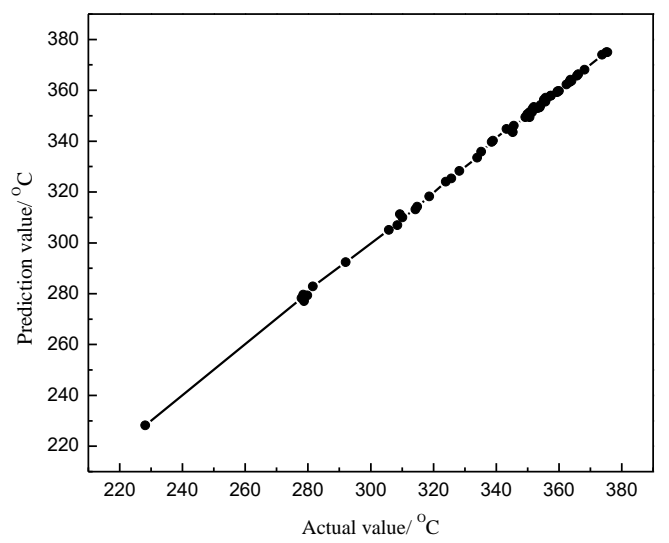

Figure 4. Contrastive analysis chart of predicted and real oil products.

It can be observed from the figure that the distribution of the predicted and actual values of the oil was similar to the straight line $y=x$; that is, the predicted value of the oil was approximately equal to the true value. The proposed new algorithm exhibited an estimated relative deviation of more than $90 \%$ of the actual oil AP (less than $0.5 \%$ ), an ARD of $0.17 \%$ for all oils, and a maximum relative deviation (MRD) of $0.634 \%$. It could be proven that the proposed AP estimation algorithm provided higher accuracy in estimating the AP of the oil substances used in the test.

\subsection{Comparison of New Algorithm and Common Models}

The test results are illustrated in Figure 5.

As is indicated in Figure 5, the Winn method had a relatively large relative deviation, while the three methods with small deviations were the newly proposed method, the Shoudeqing method, and the API method. The estimated and measured values of each method were compared, as is illustrated in Figure 6.

According to Figures 5 and 6, as the measured value of the petroleum fraction gradually increased, the trend of the Shoudeqing method became consistent with the measured value, but a large deviation occurred. The predicted values of the Albahri and Chen-Xionghua methods fluctuated significantly. In the Linden method, a higher average boiling point temperature resulted in a larger deviation. The Winn method exhibited a larger deviation in the average boiling point range below $200^{\circ} \mathrm{C}$. The new algorithm exhibited less deviation in the predicted value of the petroleum fraction used for verification. The statistics on the estimated deviations of each method are presented in Table 5. 


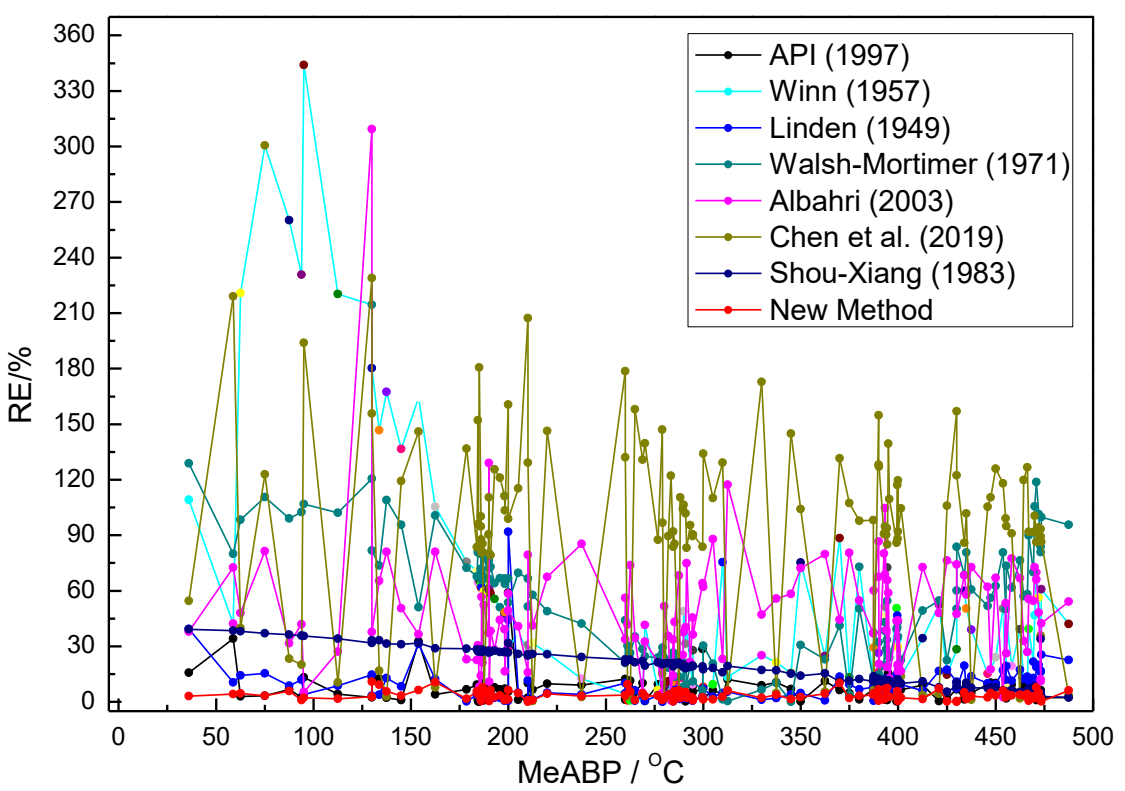

Figure 5. Error distributions of different methods and real values.

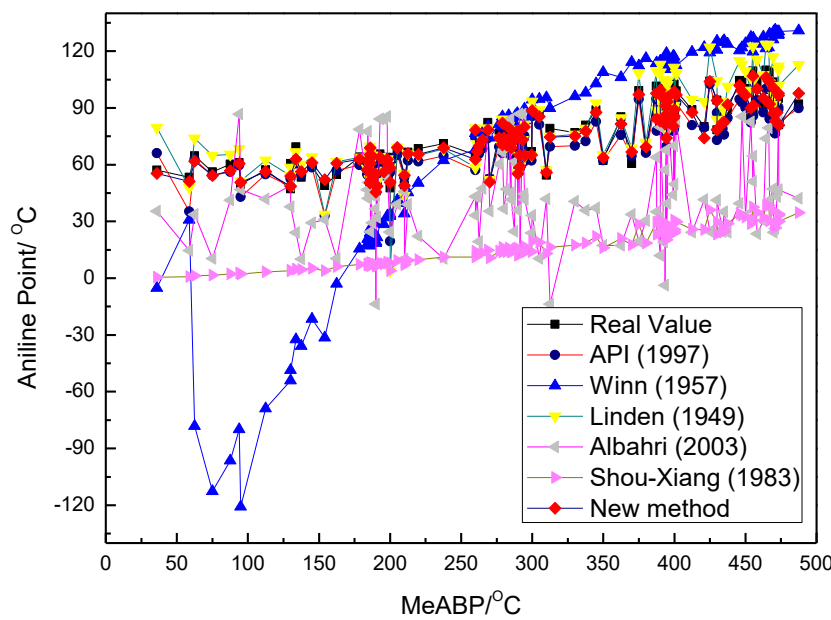

Figure 6. Trend charts of results for different methods and real values.

Table 5. Relative deviation distribution of AP estimation results of petroleum fractions.

\begin{tabular}{ccccccccc}
\hline The Relative & \multicolumn{8}{c}{ Number } \\
\cline { 2 - 8 } Error Range (\%) & API & Winn & Linden & Walsh-Mortimer & Albahri Chen & Shou & New Method \\
\hline$\leq 5 \%$ & 47 & 7 & 55 & 6 & 6 & 13 & 6 & 96 \\
$5 \%-10 \%$ & 59 & 9 & 33 & 5 & 4 & 5 & 21 & 28 \\
$10 \%-20 \%$ & 18 & 25 & 34 & 11 & 13 & 2 & 41 & 3 \\
$\geq 20 \%$ & 3 & 86 & 5 & 105 & 104 & 104 & 59 & 0 \\
\hline
\end{tabular}

In terms of the deviation distribution, the relative deviation of the new AP estimation algorithm for 96 oil test results was less than 5\%, while the other methods only yielded 55 oils with AP estimation results with a relative deviation of less than $5 \%$. The new AP estimation algorithm significantly reduced the AP estimation bias. Moreover, the AAD, ARD, maximum absolute deviation (MAD), and MRD of the test results were calculated. The results are displayed in Table 6. 
Table 6. Comparison of AP estimation results of petroleum fractions. MAD: maximum absolute deviation; MRD: maximum relative deviation.

\begin{tabular}{cccccc}
\hline Method & $\boldsymbol{N}$ & $\mathbf{A A D}\left({ }^{\circ} \mathbf{C}\right)$ & ARD (\%) & MAD $\left({ }^{\circ} \mathbf{C}\right)$ & MRD (\%) \\
\hline API & 127 & 5.17 & 7.01 & 28.14 & 59.05 \\
Winn & 127 & 34.37 & 32.61 & 70.30 & 44.03 \\
Linden & 127 & 6.38 & 8.46 & 43.80 & 51.92 \\
Walsh-Mortimer & 127 & 37.73 & 28.8 & 43.83 & 52.92 \\
Albahri & 127 & 35.36 & 47.48 & 46.18 & 59.38 \\
Chen & 127 & 40.30 & 44.71 & 47.53 & 59.00 \\
Shou & 127 & 57.74 & 18.70 & 72.08 & 28.54 \\
New method & 127 & 2.58 & 3.55 & 6.98 & 10.90 \\
\hline
\end{tabular}

As is indicated in Table 6, the ARDs of the API, Winn, Walsh-Mortimer, Linden, Albahari, Chen-Xionghua, and Shoudeqing methods were all above 5\%. Moreover, the smallest deviation of the API method reached $7.01 \%$. The ARD of the new AP estimation algorithm was approximately $3.55 \%$, which was roughly two times lower than the estimated deviation of the existing models, indicating that the proposed method could effectively improve the AP estimation accuracy.

In summary, the proposed AP estimation algorithm exhibited higher accuracy and provided a greater improvement than the commonly used algorithms did. In terms of model adaptability, the API and Albahri methods yielded a relatively accurate prediction value when the average boiling point ranged from 320.48 to $580.48 \mathrm{~K}$ and the specific gravity ranged from 0.75 to 0.90 . In particular, for the API algorithm, the ARD between the predicted and measured values of the AP was $5.33 \%$ for datapoints with an average boiling point less than $672.04 \mathrm{~K}$. For datapoints with a medium average boiling point greater than $672.04 \mathrm{~K}$, the ARD between the predicted and measured values was $10.08 \%$; therefore, this method is not applicable when calculating the average boiling point of hydrocarbon compounds or the APs of petroleum fractions greater than $672.04 \mathrm{~K}$. The proposed AP estimation algorithm had a moderate average boiling point of approximately $336.48-866.48 \mathrm{~K}$, and the specific gravity was approximately 0.65 to 1.08 . The prediction results were more accurate and offered a wider application range than those of the other algorithms. Therefore, the proposed AP estimation method provides higher accuracy and greater stability, as well as wider applicability.

\section{Conclusions}

Seven classical AP estimation methods, including the API and Winn methods, were summarized and evaluated. A new AP estimation algorithm was proposed. Through verification of the new method and a comparison to the original methods, the following conclusions could be obtained:

(1) Using experimental data, AP estimation tests were carried out on the seven methods. The results demonstrated that these algorithms generally exhibited large deviations in the calculation of APs. The accuracy of the API method was slightly higher than those of the other six methods, but the ARD of the AP calculation of the petroleum fraction was more than $5 \%$. The reasons for the inaccurate calculations of the original methods were analyzed and were mainly determined to be a lack of original data, simple models, simple regression methods, and no postprocessing;

(2) Using multiple linear regression, the average boiling point and specific gravity were taken as the main structural parameters. A new algorithm for the AP of petroleum fractions was developed by means of data regression and iterative correction. The superiority of this method compared to the original methods was confirmed, as it uses a wider range of experimental data to obtain a new correlation;

(3) When comparing the estimation results of APs by different models, the ARD of the new algorithm was $3.55 \%$ and the MRD was less than $7 \%$. Compared to the best existing estimation model, the AP model estimated that the ARD would be reduced by approximately twice the initial ARD and that the MRD would be reduced by approximately six times the initial ARD. 
In summary, the new algorithm for the petroleum fraction AP offers significant value, both as a theoretical algorithm and for actual oil prediction. The objective function regression-iteration correction method not only offers application potential in the estimation of petroleum fraction APs, but also provides a solid reference for other hydrocarbon material properties.

Author Contributions: Conceptualization, X.S.; Data curation, Y.C.; Formal analysis, S.X.; Project administration, S.X.; Writing-original draft, K.W.; Writing—review \& editing, K.W.

Funding: This research was funded by [Major Science and Technology Innovation Projects in Shandong Province] grant number [2018CXGC1102] And The APC was funded by [Science and Technology Department of Shandong Province].

Conflicts of Interest: The authors declare no conflict of interest

\section{Abbreviations}

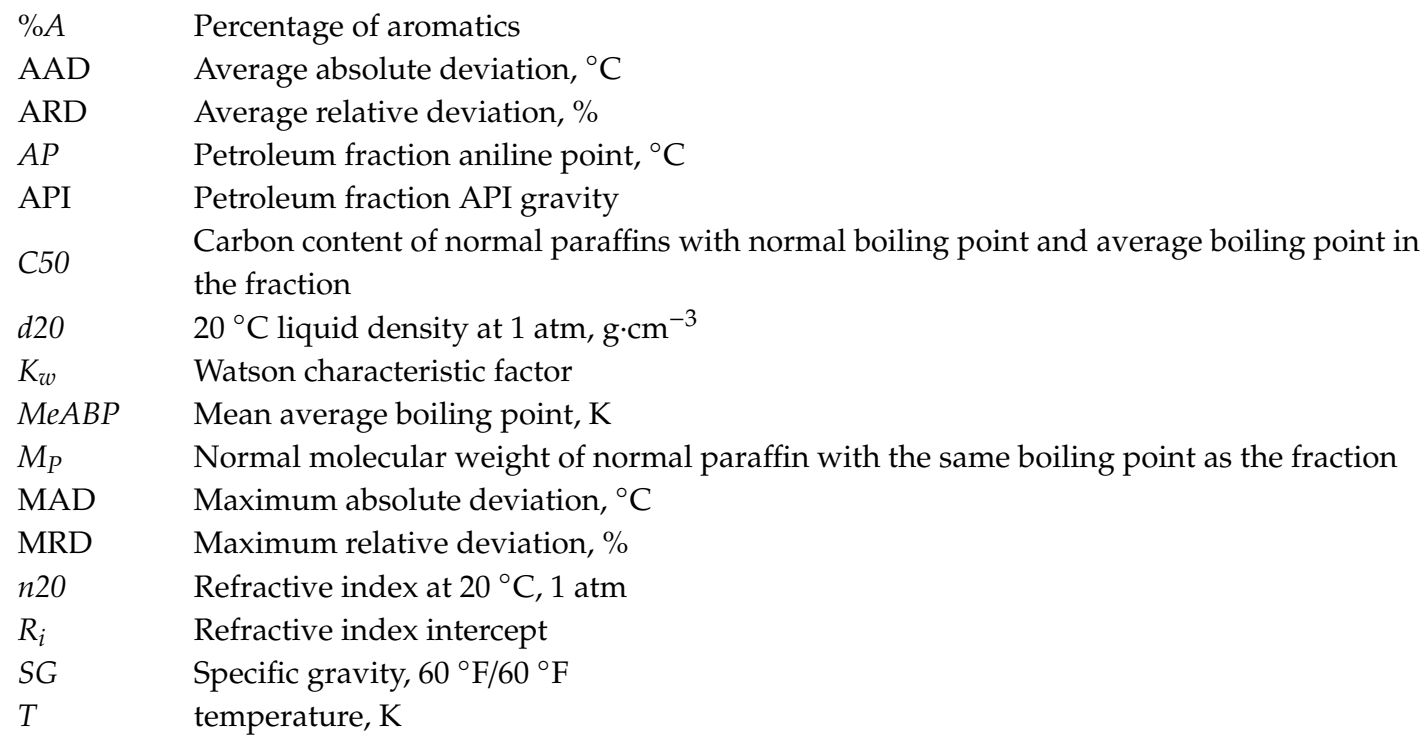

\section{Appendix A}

Table A1. Summary of 142 oil datapoints measured for regression models.

\begin{tabular}{ccccc}
\hline No. & $\begin{array}{c}\text { Specific Gravity } \\
\left(\mathbf{1 5 . 5} \mathbf{}^{\circ} \mathbf{C}\right)\end{array}$ & $\begin{array}{c}\text { Average Boiling } \\
\text { Point (K) }\end{array}$ & $\begin{array}{c}\text { Aniline Point } \\
\text { Experimental Value (K) }\end{array}$ & $\begin{array}{c}\text { New } \\
\text { Method (K) }\end{array}$ \\
\hline 1 & 0.5164 & 306.95 & 326.92 & 326.22 \\
2 & 0.5191 & 373.15 & 359.01 & 355.70 \\
3 & 0.5449 & 371.09 & 358.32 & 358.01 \\
4 & 0.5606 & 371.09 & 358.32 & 359.05 \\
5 & 0.5606 & 333.35 & 342.78 & 343.70 \\
6 & 0.5612 & 371.09 & 358.32 & 359.01 \\
7 & 0.6275 & 674.62 & 406.79 & 408.01 \\
8 & 0.6562 & 373.15 & 356.79 & 356.70 \\
9 & 0.6623 & 763.66 & 412.43 & 413.89 \\
10 & 0.6673 & 208.50 & 307.79 & 307.48 \\
11 & 0.6928 & 360.86 & 335.18 & 335.88 \\
12 & 0.7163 & 292.36 & 264.93 & 265.50 \\
13 & 0.7163 & 371.09 & 327.72 & 327.07 \\
14 & 0.7423 & 542.68 & 374.48 & 378.93 \\
17 & 0.7596 & 542.68 & 370.08 & 369.93 \\
18 & 0.7596 & 417.80 & 329.40 & 328.68 \\
\hline
\end{tabular}


Table A1. Cont.

\begin{tabular}{|c|c|c|c|c|}
\hline No. & $\begin{array}{c}\text { Specific Gravity } \\
\left(15.5^{\circ} \mathrm{C}\right)\end{array}$ & $\begin{array}{l}\text { Average Boiling } \\
\text { Point (K) }\end{array}$ & $\begin{array}{c}\text { Aniline Point } \\
\text { Experimental Value (K) }\end{array}$ & $\begin{array}{c}\text { New } \\
\text { Method (K) }\end{array}$ \\
\hline 19 & 0.7606 & 211.59 & 236.06 & 235.82 \\
\hline 20 & 0.7606 & 278.20 & 236.06 & 235.52 \\
\hline 21 & 0.7606 & 301.10 & 236.90 & 309.05 \\
\hline 22 & 0.7606 & 338.59 & 266.02 & 266.12 \\
\hline 23 & 0.7606 & 338.59 & 338.59 & 337.18 \\
\hline 24 & 0.7658 & 257.19 & 233.21 & 233.30 \\
\hline 25 & 0.8425 & 430.51 & 280.68 & 280.77 \\
\hline 26 & 0.8500 & 333.35 & 209.79 & 209.56 \\
\hline 27 & 0.8316 & 542.68 & 346.99 & 351.93 \\
\hline 28 & 0.8114 & 542.68 & 354.40 & 355.93 \\
\hline 29 & 0.8066 & 542.68 & 356.04 & 357.13 \\
\hline 30 & 0.8110 & 542.41 & 354.46 & 353.21 \\
\hline 31 & 0.8118 & 536.28 & 352.42 & 354.21 \\
\hline 32 & 0.8010 & 508.35 & 347.82 & 346.84 \\
\hline 33 & 0.8222 & 508.35 & 338.98 & 337.84 \\
\hline 34 & 0.8440 & 367.67 & 232.41 & 232.51 \\
\hline 35 & 0.8460 & 367.67 & 231.25 & 230.51 \\
\hline 36 & 0.7930 & 371.09 & 269.51 & 268.29 \\
\hline 37 & 0.8370 & 371.09 & 238.86 & 239.29 \\
\hline 38 & 0.8232 & 672.28 & 378.54 & 378.09 \\
\hline 39 & 0.8217 & 360.86 & 199.07 & 198.42 \\
\hline 40 & 0.8001 & 317.87 & 317.87 & 316.45 \\
\hline 41 & 0.8477 & 752.27 & 385.48 & 388.18 \\
\hline 42 & 0.7772 & 257.16 & 227.24 & 227.82 \\
\hline 43 & 0.8104 & 194.58 & 211.34 & 211.82 \\
\hline 44 & 0.7658 & 257.16 & 172.40 & 172.82 \\
\hline Boscan & 1.0354 & 746.00 & 328.42 & 327.28 \\
\hline Buzurgan & 1.0285 & 661.00 & 297.48 & 295.56 \\
\hline Cambimas vacuum & 1.0298 & 622.00 & 274.46 & 274.82 \\
\hline D.A. feed crack stock & 1.0246 & 687.00 & 311.70 & 310.31 \\
\hline D.A. feed lube oil & 1.0231 & 693.00 & 314.96 & 314.85 \\
\hline D-1 diesel oil (avg) & 0.9541 & 578.00 & 299.99 & 299.45 \\
\hline $\mathrm{DAOC4}$ & 1.0100 & 781.00 & 348.12 & 347.71 \\
\hline DAO L.O & 1.0246 & 804.00 & 348.45 & 349.11 \\
\hline Diesel oil T-097-96 & 0.9529 & 578.00 & 300.75 & 300.42 \\
\hline F.C.C. heavy gas oil M.C. & 1.0000 & 688.00 & 324.35 & 324.94 \\
\hline Gasoline 31 API \#1 & 0.9321 & 572.00 & 310.29 & 310.68 \\
\hline Hydroc. Feed VGO & 1.0025 & 697.00 & 326.44 & 327.22 \\
\hline Kerosene 31 API \#2 & 0.9242 & 574.00 & 315.78 & 315.79 \\
\hline Kuwait crude cut \#7 & 0.8753 & 613.00 & 351.52 & 353.09 \\
\hline Kuwait vacuum & 1.0254 & 682.00 & 309.12 & 308.80 \\
\hline Petroleum cut \#2 & 0.9590 & 578.00 & 296.84 & 296.15 \\
\hline Petroleum cut \#3 & 0.9710 & 447.00 & 202.84 & 202.22 \\
\hline Vacuum gas oil 31 API \#2 & 0.9485 & 713.00 & 352.44 & 353.87 \\
\hline $\begin{array}{c}\text { Vacuum gas oil crude } \\
\text { assay } 91\end{array}$ & 0.9107 & 676.00 & 355.81 & 354.47 \\
\hline Arabian light atmosphere & 1.0328 & 740.00 & 327.59 & 325.75 \\
\hline Athambasaca & 1.0366 & 697.00 & 309.57 & 311.28 \\
\hline $\begin{array}{l}\text { Atmospheric residue } \\
\text { crude assay } 84\end{array}$ & 0.9189 & 752.00 & 369.49 & 370.60 \\
\hline $\begin{array}{l}\text { Atmospheric residue } \\
\text { crude assay } 91\end{array}$ & 0.9189 & 752.00 & 369.49 & 369.62 \\
\hline $\begin{array}{l}\text { Atmospheric residue } \\
\text { crude assay } 94\end{array}$ & 0.9107 & 748.00 & 370.86 & 371.99 \\
\hline
\end{tabular}


Table A1. Cont.

\begin{tabular}{|c|c|c|c|c|}
\hline No. & $\begin{array}{c}\text { Specific Gravity } \\
\left(15.5^{\circ} \mathrm{C}\right)\end{array}$ & $\begin{array}{l}\text { Average Boiling } \\
\text { Point (K) }\end{array}$ & $\begin{array}{c}\text { Aniline Point } \\
\text { Experimental Value (K) }\end{array}$ & $\begin{array}{c}\text { New } \\
\text { Method (K) }\end{array}$ \\
\hline Cold Lake & 1.0513 & 722.00 & 312.24 & 313.25 \\
\hline DAO C5 & 1.0209 & 772.00 & 341.91 & 342.37 \\
\hline Deasphalting unit DAO C4 & 0.9800 & 548.00 & 262.43 & 262.36 \\
\hline Deasphalting unit DAO C5 & 0.9923 & 772.00 & 352.01 & 352.48 \\
\hline $\begin{array}{l}\text { Deasphalting unit } \\
\text { DAO(lube oil) }\end{array}$ & 1.0000 & 804.00 & 356.52 & 355.45 \\
\hline Deasphalting unit feed & 0.9760 & 525.00 & 249.21 & 249.11 \\
\hline Deasphalting unit feed & 1.0030 & 739.00 & 339.64 & 338.55 \\
\hline $\begin{array}{c}\text { Deasphalting unit feed } \\
\text { lube oil }\end{array}$ & 0.9979 & 693.00 & 327.13 & 327.85 \\
\hline Diesel oil T-106-96 & 0.9491 & 578.00 & 303.13 & 302.45 \\
\hline FCC H. G.O cut M.C. & 1.0030 & 688.00 & 322.93 & 325.08 \\
\hline Gasoline 31 API \#2 & 0.9367 & 583.00 & 313.03 & 313.20 \\
\hline Hydroc. VGO & 1.0000 & 683.00 & 322.49 & 322.65 \\
\hline Jobo & 1.0768 & 728.00 & 301.12 & 300.98 \\
\hline Kerosene 31 API \#1 & 0.9240 & 585.00 & 320.87 & 320.79 \\
\hline Kerosene 31 API \#3 & 0.9250 & 573.00 & 314.86 & 315.05 \\
\hline Kerosene 31 API \#4 & 0.9321 & 573.00 & 310.79 & 311.45 \\
\hline Kuwait crude cut \#1 & 0.8528 & 543.00 & 338.35 & 338.70 \\
\hline Kuwait crude cut \#2 & 0.8551 & 553.00 & 340.91 & 340.61 \\
\hline Kuwait crude cut \#3 & 0.8577 & 563.00 & 343.21 & 343.94 \\
\hline Kuwait crude cut \#4 & 0.8624 & 573.00 & 344.56 & 343.28 \\
\hline Kuwait crude cut \#5 & 0.8635 & 583.00 & 347.22 & 348.32 \\
\hline Kuwait crude cut \#6 & 0.8712 & 593.00 & 347.31 & 348.95 \\
\hline Kuwait crude cut \#8 & 0.8811 & 623.00 & 352.20 & 354.15 \\
\hline Marine diesel oil (avg) & 0.9529 & 576.00 & 299.65 & 299.65 \\
\hline Marine diesel oil T-075-96 & 0.9491 & 576.00 & 302.06 & 301.48 \\
\hline Marine diesel oil T-093-96 & 0.9491 & 576.00 & 302.06 & 301.02 \\
\hline Petroleum cut \#1 & 0.9590 & 576.00 & 295.70 & 295.15 \\
\hline Petroleum cut \#4 & 0.9740 & 475.00 & 217.15 & 218.16 \\
\hline Petroleum cut \#5 & 0.9740 & 508.00 & 238.79 & 238.61 \\
\hline Residue 31 API \#1 & 0.9491 & 740.00 & 159.33 & 158.34 \\
\hline Residue 31 API \#2 & 0.9491 & 681.00 & 343.64 & 344.54 \\
\hline Saudi Arabia vacuum & 1.0335 & 670.00 & 298.95 & 299.76 \\
\hline Tar sand triangle & 1.0355 & 743.00 & 327.39 & 328.30 \\
\hline TIA Juan vacuum & 1.0832 & 620.00 & 230.52 & 228.77 \\
\hline Vacuum gas oil 31 API \#1 & 0.9402 & 651.00 & 338.01 & 338.39 \\
\hline Vacuum gas oil 31 API \#3 & 0.9491 & 677.00 & 342.47 & 343.92 \\
\hline $\begin{array}{c}\text { Vacuum gas oil crude } \\
\text { assay } 94\end{array}$ & 0.9065 & 662.00 & 353.71 & 353.69 \\
\hline Aboozar & 0.8370 & 269.85 & 318.70 & 318.22 \\
\hline Abualbu & 0.8425 & 279.85 & 345.61 & 346.02 \\
\hline Alba & 0.8477 & 289.85 & 323.94 & 324.04 \\
\hline Alif & 0.8528 & 299.85 & 328.28 & 328.22 \\
\hline Amna & 0.8577 & 309.85 & 349.32 & 349.39 \\
\hline Arabhy & 0.8624 & 319.85 & 349.95 & 350.55 \\
\hline Arablt1 & 0.8712 & 339.85 & 353.09 & 352.95 \\
\hline Arablt2 & 0.8753 & 349.85 & 354.15 & 354.18 \\
\hline Arabmd1 & 0.9189 & 388.85 & 350.69 & 349.43 \\
\hline Arabmd2 & 0.9240 & 402.85 & 351.47 & 351.36 \\
\hline Arimbi & 0.9710 & 474.85 & 351.99 & 353.44 \\
\hline
\end{tabular}


Table A1. Cont.

\begin{tabular}{|c|c|c|c|c|}
\hline No. & $\begin{array}{c}\text { Specific Gravity } \\
\left(15.5^{\circ} \mathrm{C}\right)\end{array}$ & $\begin{array}{c}\text { Average Boiling } \\
\text { Point (K) }\end{array}$ & $\begin{array}{c}\text { Aniline Point } \\
\text { Experimental Value (K) }\end{array}$ & $\begin{array}{c}\text { New } \\
\text { Method (K) }\end{array}$ \\
\hline Ashtart & 0.9800 & 478.85 & 350.62 & 351.40 \\
\hline Attaka & 0.9760 & 478.85 & 351.60 & 352.73 \\
\hline Auk & 0.7772 & 311.85 & 373.79 & 373.98 \\
\hline Cabinda & 0.8001 & 300.85 & 365.79 & 365.71 \\
\hline Canseco & 0.8066 & 299.85 & 364.05 & 363.61 \\
\hline Canolimo & 0.8110 & 299.85 & 362.45 & 362.30 \\
\hline Ceuta & 0.8316 & 298.85 & 355.68 & 355.50 \\
\hline Champion & 0.8551 & 309.85 & 350.20 & 350.34 \\
\hline Cinta & 0.9065 & 377.85 & 350.39 & 350.85 \\
\hline Cldlakbl & 0.9367 & 439.85 & 355.87 & 356.30 \\
\hline Cooperbs1 & 0.9189 & 403.85 & 353.92 & 353.35 \\
\hline Cormora1 & 1.0025 & 466.85 & 338.96 & 340.12 \\
\hline Cormora2 & 1.0285 & 407.85 & 308.54 & 306.98 \\
\hline Cusiaba & 0.8217 & 302.85 & 360.02 & 359.74 \\
\hline Daihung & 0.8232 & 302.85 & 359.48 & 359.26 \\
\hline Dan & 0.8114 & 304.85 & 363.45 & 363.35 \\
\hline Danish & 0.8104 & 304.85 & 363.42 & 363.35 \\
\hline Djenobl & 0.8222 & 302.85 & 359.65 & 359.58 \\
\hline Dorrood & 0.8118 & 304.85 & 363.45 & 363.23 \\
\hline Dubai & 0.7930 & 302.85 & 368.15 & 368.12 \\
\hline Dukhan & 0.8010 & 304.85 & 366.15 & 366.34 \\
\hline Dulang & 0.8440 & 173.85 & 292.08 & 292.40 \\
\hline Dunlin & 0.8460 & 201.85 & 310.14 & 310.02 \\
\hline Duri & 0.8500 & 234.85 & 325.69 & 325.27 \\
\hline Estzeitm & 1.0030 & 251.85 & 228.11 & 228.18 \\
\hline Ekofisk & 0.9590 & 274.85 & 277.94 & 278.27 \\
\hline Emerald & 0.9740 & 498.85 & 357.48 & 357.87 \\
\hline Eocene & 1.0246 & 419.85 & 314.85 & 314.19 \\
\hline Essider & 0.9321 & 530.85 & 375.45 & 375.00 \\
\hline
\end{tabular}

Table A2. Summary of 127 oil datapoints measured and used to validate the model.

\begin{tabular}{|c|c|c|c|c|c|c|}
\hline Oil Source & $\begin{array}{c}\text { Average } \\
\text { Boiling } \\
\text { Point (K) }\end{array}$ & $\begin{array}{l}\text { Specific } \\
\text { Gravity } \\
\left(15.5^{\circ} \mathrm{C}\right)\end{array}$ & $\begin{array}{c}\text { Aniline } \\
\text { Point } \\
\text { Experimental } \\
\text { Value (K) }\end{array}$ & $\begin{array}{c}\text { Average } \\
\text { Boiling } \\
\text { Point (K) }\end{array}$ & $\begin{array}{l}\text { Specific } \\
\text { Gravity } \\
\left(15.5^{\circ} \mathrm{C}\right)\end{array}$ & $\begin{array}{c}\text { Aniline } \\
\text { Point } \\
\text { Experimental } \\
\text { Value (K) }\end{array}$ \\
\hline \multirow{12}{*}{ Tarim [3] } & 309.15 & 0.6375 & 330.25 & 535.65 & 0.8358 & 347.13 \\
\hline & 335.65 & 0.6674 & 337.83 & 553.15 & 0.8393 & 348.85 \\
\hline & 360.65 & 0.702 & 333.35 & 560.65 & 0.8486 & 350.85 \\
\hline & 367.05 & 0.7018 & 334.23 & 585.65 & 0.8645 & 352.35 \\
\hline & 385.65 & 0.728 & 330.45 & 610.65 & 0.8755 & 353.95 \\
\hline & 406.85 & 0.7365 & 342.5 & 635.65 & 0.8835 & 358.37 \\
\hline & 410.65 & 0.7526 & 326.4 & 660.65 & 0.8946 & 361.27 \\
\hline & 435.65 & 0.7701 & 327.95 & 685.65 & 0.902 & 362.15 \\
\hline & 460.65 & 0.7834 & 334.6 & 694.15 & 0.9118 & 353.15 \\
\hline & 485.65 & 0.8024 & 339.65 & 710.65 & 0.9062 & 362.15 \\
\hline & 510.75 & 0.8172 & 344.3 & 735.65 & 0.9119 & 364.77 \\
\hline & 534.35 & 0.831 & 347.2 & 760.65 & 0.9196 & 365.2 \\
\hline \multirow{4}{*}{ Dagang [16] } & 331.95 & 0.7112 & 326.55 & 603.15 & 0.8767 & 350.00 \\
\hline & 403.15 & 0.7584 & 320.40 & 663.15 & 0.8860 & 362.28 \\
\hline & 483.15 & 0.8236 & 327.60 & 703.15 & 0.8928 & 367.15 \\
\hline & 533.15 & 0.8586 & 338.25 & & & \\
\hline
\end{tabular}


Table A2. Cont.

\begin{tabular}{|c|c|c|c|c|c|c|}
\hline Oil Source & $\begin{array}{l}\text { Average } \\
\text { Boiling } \\
\text { Point (K) }\end{array}$ & $\begin{array}{l}\text { Specific } \\
\text { Gravity } \\
\left(15.5^{\circ} \mathrm{C}\right)\end{array}$ & $\begin{array}{c}\text { Aniline } \\
\text { Point } \\
\text { Experimental } \\
\text { Value (K) }\end{array}$ & $\begin{array}{c}\text { Average } \\
\text { Boiling } \\
\text { Point (K) }\end{array}$ & $\begin{array}{c}\text { Specific } \\
\text { Gravity } \\
\left(15.5^{\circ} \mathrm{C}\right)\end{array}$ & $\begin{array}{c}\text { Aniline } \\
\text { Point } \\
\text { Experimental } \\
\text { Value (K) }\end{array}$ \\
\hline \multirow{3}{*}{ Shengli [7] } & 368.15 & 0.7345 & 322.65 & 538.15 & 0.8298 & 345.52 \\
\hline & 458.15 & 0.7956 & 328.10 & 618.15 & 0.8508 & 362.10 \\
\hline & 473.15 & 0.8073 & 332.12 & 668.15 & 0.8691 & 368.95 \\
\hline \multirow{3}{*}{ Renqiu [7] } & 403.15 & 0.7495 & 333.65 & 573.15 & 0.8132 & 360.51 \\
\hline & 493.15 & 0.8100 & 341.51 & 663.15 & 0.8418 & 372.06 \\
\hline & 533.15 & 0.8118 & 348.89 & 723.15 & 0.8968 & 373.29 \\
\hline \multirow{3}{*}{$\begin{array}{c}\text { Yangsanmu } \\
\text { [7] }\end{array}$} & 427.15 & 0.8243 & 322.08 & 583.15 & 0.9062 & 327.56 \\
\hline & 483.15 & 0.8504 & 322.46 & 643.15 & 0.9295 & 333.74 \\
\hline & 543.15 & 0.883 & 325.56 & 703.15 & 0.9434 & 351.42 \\
\hline \multirow{3}{*}{ Daqing [7] } & 348.15 & 0.6931 & 329.35 & 578.15 & 0.8271 & 359.65 \\
\hline & 418.15 & 0.7509 & 332.25 & 648.15 & 0.8399 & 372.25 \\
\hline & 478.15 & 0.7888 & 339.05 & 698.15 & 0.8489 & 377.25 \\
\hline \multirow{4}{*}{ Gudao [7] } & 463.15 & 0.8278 & 320.25 & 653.15 & 0.9306 & 340.38 \\
\hline & 473.15 & 0.9484 & 320.80 & 708.15 & 0.9356 & 356.75 \\
\hline & 563.15 & 0.8912 & 330.45 & 743.15 & 0.9456 & 362.00 \\
\hline & 623.15 & 0.9211 & 335.30 & & & \\
\hline \multirow{33}{*}{$\begin{array}{l}\text { Unknown } \\
\text { source of } \\
\text { petroleum } \\
\text { fraction }\end{array}$} & 451.65 & 0.7784 & 337.15 & 572.75 & 0.8774 & 339.95 \\
\hline & 457.05 & 0.7950 & 333.55 & 660.45 & 0.8467 & 374.65 \\
\hline & 457.55 & 0.7858 & 332.55 & 663.35 & 0.8505 & 373.55 \\
\hline & 457.75 & 0.7846 & 332.65 & 665.85 & 0.8617 & 369.35 \\
\hline & 459.05 & 0.8092 & 324.85 & 666.45 & 0.9045 & 350.15 \\
\hline & 459.15 & 0.7723 & 341.15 & 666.45 & 0.9073 & 353.15 \\
\hline & 459.25 & 0.7804 & 338.65 & 667.05 & 0.8761 & 366.45 \\
\hline & 459.35 & 0.7902 & 329.95 & 667.35 & 0.8921 & 356.65 \\
\hline & 459.75 & 0.8052 & 330.95 & 667.55 & 0.9292 & 342.05 \\
\hline & 459.85 & 0.8071 & 329.35 & 668.65 & 0.8641 & 371.65 \\
\hline & 462.95 & 0.8043 & 331.55 & 672.45 & 0.9028 & 351.15 \\
\hline & 463.35 & 0.8260 & 322.05 & 672.65 & 0.9020 & 353.25 \\
\hline & 463.95 & 0.8165 & 325.15 & 672.95 & 0.8989 & 360.55 \\
\hline & 466.15 & 0.7895 & 338.75 & 673.05 & 0.8528 & 375.65 \\
\hline & 468.85 & 0.8073 & 331.35 & 673.15 & 0.8880 & 361.85 \\
\hline & 471.15 & 0.8005 & 334.45 & 674.55 & 0.8607 & 372.15 \\
\hline & 471.35 & 0.7966 & 337.05 & 707.15 & 0.9231 & 351.15 \\
\hline & 542.05 & 0.8189 & 355.35 & 719.05 & 0.8813 & 377.55 \\
\hline & 549.85 & 0.8368 & 349.75 & 720.65 & 0.8869 & 376.85 \\
\hline & 552.15 & 0.8477 & 342.95 & 726.95 & 0.9247 & 357.95 \\
\hline & 552.25 & 0.8169 & 357.15 & 728.35 & 0.8711 & 382.65 \\
\hline & 555.15 & 0.8505 & 346.15 & 728.65 & 0.9139 & 360.55 \\
\hline & 556.55 & 0.8276 & 356.05 & 731.35 & 0.8894 & 376.85 \\
\hline & 557.85 & 0.8517 & 341.15 & 737.65 & 0.8763 & 383.15 \\
\hline & 557.85 & 0.8440 & 346.75 & 739.45 & 0.8776 & 381.95 \\
\hline & 558.45 & 0.8566 & 346.15 & 740.05 & 0.9267 & 365.75 \\
\hline & 561.35 & 0.8404 & 350.95 & 742.55 & 0.8949 & 376.75 \\
\hline & 562.65 & 0.8370 & 353.45 & 744.15 & 0.9593 & 350.35 \\
\hline & 564.05 & 0.8702 & 335.05 & 745.25 & 0.9385 & 356.55 \\
\hline & 564.55 & 0.8847 & 333.25 & 746.35 & 0.9140 & 368.15 \\
\hline & 566.45 & 0.8526 & 344.45 & 746.35 & 0.9099 & 369.05 \\
\hline & 567.65 & 0.8351 & 354.95 & 746.65 & 0.9354 & 354.15 \\
\hline & 567.95 & 0.8744 & 338.45 & & & \\
\hline
\end{tabular}




\section{References}

1. Gharagheizi, F.; Tirandazi, B.; Barzin, R. Estimation of Aniline Point Temperature of Pure Hydrocarbons: A Quantitative Structure-Property Relationship Approach. Ind. Eng. Chem. Res. 2009, 48, 1678-1682. [CrossRef]

2. Guo, Y.G. Determination and Correlation of Electrochemical Oil Aniline Point. Lubr. Fuels 2016, z1, 30-31.

3. Jiang, H.Q. Prediction of the Physical Properties of Tarim Distillate Oil; China University of Petroleum: Beijing, China, 2010; pp. 58-67.

4. GB/T 262-2010. Determination of Aniline Point and Mixed Aniline Point in Petroleum Products and Hydrocarbon Solvents; Chemical Industry Press: Beijing, China, 1964; pp. 301-304. Available online: https://www.antpedia. com/standard/6159574.html (accessed on 10 September 2019).

5. Gharagheizi, F. QSPR analysis for intrinsic viscosity of polymer solutions by means of GA-MLR and RBFNN. Comput. Mater. Sci. 2007, 40, 159-167. [CrossRef]

6. Zhang, Y.Y. Prediction of aniline point of hydrocarbons based on QSPR method. J. Saf. Environ. 2015, 06, 126-131. [CrossRef] [PubMed]

7. Shou, D.Q. Study on the Basic Properties of Petroleum in China (I)—Determination and Correlation of Average Molecular Weight of Petroleum Straight Distillate. J. East China Pet. Univ. 1983, 03, 334-342.

8. Albahri, T. Specific Gravity, RVP, Octane Number, and Saturates, Olefins, and Aromatics Fractional Composition of Gasoline and Petroleum Fractions by Neural Network Algorithms. Pet. Sci. Technol. 2014, 32-35. [CrossRef]

9. Riazi, M.R. Characterization and Properties of Petroleum Fractions; Hydrocarbon Process: Washington, DC, USA, 1999; pp. 137-138.

10. American Petroleum Institute. Technical Data Book Petroleum Refining, 6th ed.; American Petroleum Institute: Washington, DC, USA, 1997; pp. 356-368.

11. Winn, E.W. Physical Properties by Nomogram. Pet. Refin. 1957, 36, 157-159.

12. Linden, H.R. The Relationship of Physical Properties and Ultimate Analysis of Liquid Hydrocarbon. Oil Gas J. 1949, 48, 60-65.

13. Walsh, R.E. New Way to Test Product Quality. Hydrocarb. Process. 1971, 50, 153-158.

14. Albahri, T.A.; Riazi, M.R.; Alqattan, A.A. Analysis of Quality of the Petroleum Fuels. Energy Fuels 2003, 17, 689-693. [CrossRef]

15. Chen, X.H.; Li, L. A new mathematical correlation of aniline points in petroleum fractions. Guangdong J. Chem. Eng. 2019, 08, 57-58. [CrossRef]

16. Shou, D.Q. Research on the Basic Properties of Petroleum in China (I). Pet. Refin. Chem. Eng. 1984, 04, 1-8.

17. Yin, C.S.; Liu, X.H.; Guo, W.M.; Liu, S.S.; Han, S.K.; Wang, L.S. Multi-objective modeling and assessment of partition properties: A GA-based quantitative structure-property relationship approach. Chin. J. Chem. 2003, 21, 1150-1158. [CrossRef]

18. Jenkins, G.I. Quick Measure of Jet Fuel Properties. Hydrocarb. Process. 1968, 47, 161-164.

19. Riazi, M.; Albahri, T.; Alqattan, A. Prediction of Reid Vapor Pressure of Petroleum Fuels. Pet. Sci. Technol. 2005, 23, 75-86. [CrossRef]

20. Gary, J.H.; Handwerk, G.E.; Kaiser, M.J. Petroleum Refining: Technology and Economics[M]; CRC Press: Boca Raton, FL, USA, 2007.

21. Li, W. Research on Small Sample Multivariate Experimental Design and Optimization Analysis System; Wuhan University of Technology: Wuhan, China, 2012; pp. 4-8.

22. Xiao, S.J.; Zhu, X.F. An Improved Fast and Efficient Differential Evolution Algorithm. J. Hefei Univ. Technol. Nat. Sci. 2009, 32, 1700-1703.

23. Albahri, T.A. Prediction of the aniline point temperature of pure hydrocarbon liquids and their mixtures from molecular structure. J. Mol. Liq. 2012, 174, 80-85. [CrossRef] 
24. Carl, L.Y. Thermophysical Properties of Chemicals and Hydrocarbons [M]; William Andrew Publishing: New York, NY, USA, 2008; p. 802.

25. Speight, J.G. The Chemistry and Technology of Coal, 2nd ed.; CRC Press: Boca Raton, FL, USA, 1983; Volume 36, pp. 170-172.

(C) 2019 by the authors. Licensee MDPI, Basel, Switzerland. This article is an open access article distributed under the terms and conditions of the Creative Commons Attribution (CC BY) license (http://creativecommons.org/licenses/by/4.0/). 